\title{
Empirical Evidence of Co-Movement between the Canadian CDS, Stock Market And TSX 60 Volatility Index: A Wavelet Approach
}

\author{
Ramzan Ali ${ }^{*}$, Usman Ullah ${ }^{2}$, Musa Khan ${ }^{3}$, Muhammad Shaheer ${ }^{4}$, Farhan Abbas ${ }^{5}$ \\ 1,5 School of Accounting and Finance, The University of Lahore, Pakistan \\ 2,3 Department of Management Sciences, Superior University, Lahore, Pakistan \\ ${ }^{4}$ Universiti Utara, Malaysia \\ * Corresponding author: ramzan.ali@gmail.com
}

\section{Article History \\ Received 2020-04-06 \\ Revised 2020-04-28 \\ Accepted 2020-04-28 \\ Published 2020-05-19}

\section{Keywords}

Covariance

Wavelet Analysis

Time-series

Co-movement

Correlation

\section{How to cite?}

Ali, R., Ullah, U., Khan, M., Shaheer,

M., \& Abbas, F. (2020). Empirical

Evidence of Co-Movement Between The

Canadian CDS, Stock Market And

TSX 60 Volatility Index By Using A

Wavelet Approach. SEISENSE Journal

of Management, 3(3), 51-64.

doi:10.33215/sjom.v3i3.353
Abstract

Purpose- The prime objective of this study was to find the comovement between the Canadian credit default swaps market, the Stock market and volatility index (TSX 60 Index)

Design/ Methodology- To achieve this purpose, daily data containing 2870 observations starting from the 1 st of January 2009 to the 30th of December 2019 were analyzed. This study employed the wavelet approach to present results in short-term, mediumterm, long-term, and very long time.

Findings- The findings of this study showed a negative correlation between the CDS market, stock market, and the TSX 60 index in the short-term as well as in the long-term term, while in mediumterm and very long-term period correlation is strongly positive. The wavelet co-movement results in the short-term and long-term were negative, while this relationship in the medium-term and very longterm period was strongly positive.

Practical Implications- This research provides simultaneous valuable information for investment decisions in the short, medium, and long term time horizons, as well as for the policymakers in the Canadian credit default swaps market, stock market, and the volatility index (TSX 60 Index). 


\section{Introduction}

Over the last decade, stock markets around the globe and particularly in the Canadian Credit Default Swaps market has increased. As per the real authorized figures by the Canada National Statistical Agency in January 2009, the total value of Credit Default Swaps (CDS) market in Canada was US\$ 470,377 billion while in December 2019 the total value of CDS market in Canada has almost doubled to US\$ 746,224 billion (CNSA, 2019). Therefore, not only non-financial corporations are a part of the CDS market, but also the Canadian pension funds have entered the market for gaining rewards on investment. The intriguing fact is that international insurance companies are participating more rather than domestic companies. However, over the last two years, the demands of the CDS market have shown strong growth by Canadian institutions and continuously increased the market player's confidence to deal with this product. The CDS market plays a vital role in financial stability and mitigate credit risk (Reid, 2005; Meo et al., 2018). The CDS market faced the toughest challenge from the 2007-2009 credit crisis, and mostly Greece, Argentina, United States, and European Union countries were severely affected by this crisis. The CDS market first crisis in 2007, which was named as Big Bang and the other one was termed as Small Bang in 2009. The post-crisis US CDS market introduced structural changes in 2013. In 2011 European Union countries issued the Dodd-Frank Act (Holden and Jacobsen, 2014; Mishra et al., 2019; Chang et al., 2019; Hameed et al., 2019; Meo et al., 2019; Hussain et al., 2017; Khan et al., 2018).

The last decade Credit derivative market witnessed substantial growth, and the most popular financial instrument in the derivative market has been credit default swaps, which market offers to trade credit risk. The credit risk should be reflected by the market price of financial services firms like CDS, bonds, and the stock market. In developed countries, capital markets when credit risk change reflect in both equity and debts providing firms concurrently (Park, 2013; Fareed et al., 2018; Arain et al., 2019; Rasheed et al., 2019; Arain et al., 2019; Masood et al., 2015; Meo et al., 2018). The CDS contract is a bilateral agreement between two parties, i.e., the buyer and seller. Seller protection is provided through some underlying reference entity in the shape of bonds. While buyer protection is done through the CDS agreement can hedge the total amount of credit a borrower can get. However, when the borrower, in the case of default or termination of the contract, the seller should be liable to pay to the buyer nominal value of the contract or adopt the alternatives cash settlement methods. After the 2007 economic crisis, the International Swaps and Derivatives Association (ISDA) developed a Master Confirmation Agreement according to which companies established a committee to take a binding decision whenever any credit event occurs and then initiate the bilateral negotiation, while in the case of default the CDS contract is auctioned through biding (Board, 2012; Awan et al., 2018; Meo et al., 2018).

The financial market instrument plays a vital role in challenging decision making from lender to borrower. The credit derivative contract transfers the risk and yield from one party to another through the futures, options, and CDS contracts. However, the CDS contract has most commonly been used, and in this arrangement, two parties promise payment of the loan and give minimum premium payment to the lender. Therefore a contract market has emerged since the late 1990s by International Swap Derivative Association (ISDA) and risk-taking insurance companies has been ensured the protection of investment. Hence for any price change in the market, both parties have a right to re-write the contract after bilateral negotiations (Esen, Zeren and Şimdi, 2015; Meo et al., 2017). The CDS market work as over the counter market (OTC), which market protection of seller compensation pay to a buyer. Hence due to credit protection, buyers should be paid a fixed premium, which is known as CDS spread. The CDS market has an open opportunity for sellers to mitigate their investment risk. The CDS market growth is a tool to understand the performance of the financial market. Any change in credit risk reflects CDS spread, which is ultimately linked to the microeconomic factors (Kar, Bayat and Kayhan, 2016; Meo et al., 2018). 
Many economic factors have been involved in developed countries' growth, which includes natural resources, human capital, technology, infrastructure, exports, foreign direct investment, GDP, industrial growth while the CDS market, stock market, and volatility VIX index is one of leading prime indicator of economic growth. Several studies have found long-term and short-term relationships between the co-movement about Canadian CDS, stock market, and TSX 60 volatility index by utilizing different methods or approaches. The result estimated via the Credit Grades (CG) model and the stock implied model which shows the interconnection among the credit default swap and the stock market and unveils negative relationships (Schweikhard and Tsesmelidakis, 2013; Meo et al.,2017), the method has been used in this paper. Pearson correlation coefficient and (VAR) vector autoregressive model hence the result showed the relationship between CDS and stock market significantly negative or inverse relationship (Fung, Sierra, Yau and Zhang, 2008), the paper which used VAR model and GARCH model to find the relationship between two variables showed the CDS and stock return are a significantly negative related (Park, 2013), they used multivariate regression and different statistical regression tests and found negative and significant relation among them (Baran et al., 2018). Before the occurrence of the great financial crisis in 2007-2009, the Canadian credit default swaps market worth $\$ 61.2$ trillion while at the end of 2007 was $\$ 9.4$ trillion, and according to Policy Alternative publisher, almost 4 lac peoples were unemployed during this crisis. Hence during the crisis, the Canadian government put $\$ 200$ billion in a bank of Canada while the international swaps derivatives association has reviewed the CDS market contract standard to safeguard the interest of investors. Previous studies found long run and short relationship among CDS, stock market and TSX 60 index. A decade after these crisis the Canadian CDS market has showed a tremendous growth and now the CDS market shares is $32.8 \%$ of the total Canadian economy which has now become a vital area of study for Canadian economy.

The remaining part of this article consists of the comprehensive literature review, data and methodology, empirical findings, and conclusion of the study.

\section{Literature Review}

In the study of the relationship between the credit default swap (CDS) and stock market as well as CDS and volatility index, researchers around the globe employed various theoretical approaches. However, this is one of the significant causes that mark the relationship even more motivating. Two primary theories discussed in the literature on the association concerning the CDS, stock market, and the volatility indexes.

Shahzad, Aloui, and Jammazi (2019) endeavored to find out the sectorial relationship between CDS and the stock market as well as CDS and volatility index in USA and data for US sectorial consists of banking, financial institutions, telecommunication, health care, oil \& gas, primary material, consumer goods, utility, industrial, consumer service and technology while the sample period from the 14th of December 2007 to the 21st of September 2018. The method was used bivariate wavelet coherence and the multivariate wavelet coherence test run under the wavelet approach. Overall findings of the paper showed a negative relationship between credit default swap and stock price and a significant positive relationship among CDS and volatility index.

Norden and Weber (2004) investigated the feedback of the stock and credit default swap market to rating published formed by the three major rating agencies from 2000 to 2002 and used AR (Abnormal Return) method in this study. The result showed that both markets have negative relationships with all three major agencies. Secondly, the different rating events evaluate for downgrades by standard \& poor and moody through different combined analyses, thirdly the importance of unprecedented performance in both the market influence by the old level rating.

The impact of government involvement on credit default swap and the stock market was examined by taking into account the financial crises period of 2007 to 2009. The results estimated via a Merton type structure 
model, the CG model, and the stock implied model. The study revealed that the relationship between credit default swap and the stock market is negative because the stock implied credit is a higher risk then CDS (Schweikhard and Tsesmelidakis, 2013). According to Asandului, Lupu, and Claudiu MURSA (2015); Ali et al., (2019) the relationship between credit default swap and a stock market in Eastern European countries was studied by utilizing the data from 2004 to 2014. The analysis estimated through structural breaks and cointegration developed by VAR models. The results reported in this study were classified after, and before the financial crisis, the stock market played a crucial role in price discovery. The relationship between credit default swap and the stock market is an inverse relationship in this study. Hkiri, Hammoudeh, Aloui, and Shahbaz (2018); Meo et al., (2018) explained the relationship of the credit default swap spread for financial services firms, insurance, and US banks with major global factors including stock market, Libor, treasury bills rate and oil prices. The study examined through the Partial Wavelet and multi-wavelet method. The finding of the paper shows that the credit default swap established a significant and positive interrelationship with the oil price factor.

Additionally, Shahzad, Nor, Hammoudeh, and Shahbaz (2017) explored the relationship between the US industry sector's credit default swap and the stock market. The data used for the period starting from the 14th of December, 2007, and ended on the 31st of December, 2014, selected the eleven US industrial sectors. This paper analyzed the relationships via the VAR model and Granger causality to examine non-linear links among the dependent and independent variables. The study suggested that all the stock market relationships with CDS are parallel in some industrial sectors, including banking, healthcare and material industries, the Granger causality result showed that the CDS and stock relationships depend on time and investment decisions. Tokmakçioğlu, Özçelebİ, and Manİoğlu (2018); Ali, Z. Z. Butt, and Butt (2019) and Meo et al., (2020) worked to check the impact of credit default swap on the stock index in BRIC countries. The sample size of the study ranges from February 2010 to March 2018. This study employed the VAR and ARDL models to check the BRIC nation's economic relations. Paper found a 95\% significant inverse relationship among variables.

Moreover, Tolikas and Topaloglou (2017) examined the default risk price faster in the credit default swap market. The stock market in the leading economic sectors of North America, Europe, the United Kingdom, and Asia and data consists from $1^{\text {st }}$ of January 2008 to the 30th of June 2014 while the method used was vector auto-regression model (VAR), regression analysis, descriptive statistical analysis, and standard deviation model. However, the result has been given in this paper; the stock market is more efficient than the CDS market because the price discovery process is better than the credit default swap market and also results showed that there is no significant feedback effect from the credit default swap market to the stock market. Zghal, Ghorbel, and Triki (2018) described that whether the credit default swap can act as a protection and safe-haven for the European stock sectors, and for this purpose data from December 2007 to September 2017 was evaluated. The paper measures the results via the dynamic conditional correlation model and asymmetric dynamic conditional correlational model after a thorough investigation of the strong relationship between CDS and European stock sectors.

\section{Methodology}

\section{Variable and Data Source}

The present study consists of 2870 daily observation started from the 1 st of January, 2009, to the 31st of December, 2019. In the present study, three variables are being used, namely the stock market index, volatility index, and credit default swap. Data were collected from (World Bank Development Indicators (WDI), Canada National Statistical Agency, and S\&P Dow Jones Indices. The subject study utilized the credit default swap (CDS) market showed as a dependent variable while the stock market and volatility index as independent variables. There are other studies also focused on these variables and employed wavelet correlation analysis 
(Shahzad, Aloui, and Jammazi, 2019; Hkiri et al., 2018; Shahzad, Nor, Sanusi, et al., 2017). The normal functional form of the model is given as in the following.

$\mathrm{CDS}=f($ Stock market, TSX 60 Volatility index $)$

Table 1 - Variables Description and Source

\begin{tabular}{llll}
\hline Variables & Description & Units & Source \\
\hline CDS & Credit Default & $\begin{array}{l}\text { Provide Guaranteed Loan by Bank of Canada } \\
\text { (current US\$) }\end{array}$ & $\begin{array}{l}\text { Canada National Statistical } \\
\text { Agency (CNSA) }\end{array}$ \\
Sw & Stock Market & $\begin{array}{l}\text { The market capitalization of listed domestic } \\
\text { companies (current US\$) }\end{array}$ & WDI \\
VIX & Volatility Index & TSX 60 volatiity Index (\%) & S\&P Dow Jones Indices \\
Index & & &
\end{tabular}

This study has utilized the time-series data to evaluate short-term, medium-term, long-term, and very long-term relationships between the credit default swap market, stock market, and TSX 60 VIX index. The econometric model of the study is as follows.

$$
C D S_{t}=\beta_{0}+\beta 1\left(S M_{t}\right)+\beta 2\left(T S X 60_{t}\right)
$$

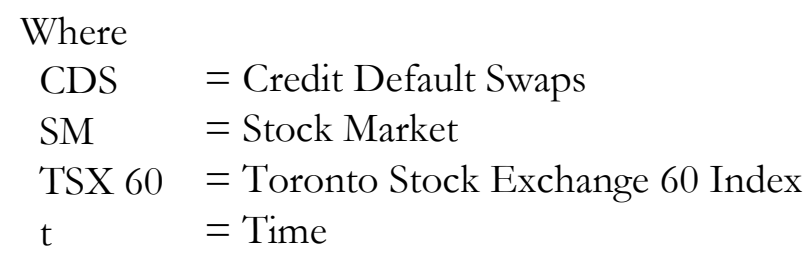

\section{Wavelet approach time-frequency dynamic in correlations}

Rua (2012) described that the primary branch of mathematics leading to wavelet founded by Joseph Fourier in 1807 with the theories of frequency analysis. The central role of the wavelet approach is to divide the data into different parts and analyzed the relationship between the variable, which includes short term, medium term, longterm, and very long term. Rua (2012) alos defined that in 1981, jean Morlet, worked as a geophysicist for a French oil company the Morlet wavelet developed an equation to solved the signal processing problem for oil exploring company. The equation can be written as:

$$
\psi(t)=\pi^{-\frac{1}{4}} e^{i \omega_{0} t} e^{\frac{-t^{2}}{2}}
$$

The Morlet wavelet is challenging to understand because it allows both time-dependent amplitude and stages of different frequencies Shahbaz, Tiwari, and Tahir (2015) the CWT (Continuous Wavelet Transform) considered both time and frequencies the advantage of CWT is that it can be differentiated by localizing time $(\Delta t)$ and frequencies $(\Delta \omega)$ or both. The Morlet wavelet used in research as following equation. Rua (2010) wavelet has limited but compact support; hence they grow and decay within a limited period so, which define as:

$$
\psi_{\tau, s}(t)=\frac{1}{\sqrt{s}} \psi\left(\frac{t-\tau}{s}\right)
$$

Where $\tau$ is showed as the time position, $\mathrm{s}$ is the scale or parameter, $\frac{1}{\sqrt{s}}$ is a normalization factor comparable through time and scale while sing $\psi$ showed the frequency. 
Aguiar-Conraria, Azevedo, and Soares (2008), there are multiple types of wavelet. Still, the most popular wavelet type is Morlet wavelet which provides combine information, including different time series and frequency, which define as:

$$
\psi_{\eta}(t)=\pi^{-\frac{1}{4}}\left(e^{i \eta t}-e^{-\frac{\eta^{2}}{2}}\right) e^{-\frac{t^{2}}{2}}
$$

The term $e^{-\frac{\eta^{2}}{2}}$ is introduce to guarantee while $\eta \geq 5$ this term is insignificant the most straightforward or normal used function as Morlet wavelet is following:

$$
\psi_{\eta}(t)=\pi^{-\frac{1}{4}} e^{i \eta t} e^{-\frac{t^{2}}{2}}
$$

Huang, Hsieh, and Huang (1999), the primary function of the Morlet wavelet method is effectively monitoring the one dynamics like time-varying. Which method has been visualized of a specific area of interest and characteristic while information provides by frequency and time the formula formulation above mention in same as equation (3): Mensi, Hkiri, Al-Yahyaee and Kang (2018) considered the two or more relationship equate through wavelet decomposition method to identify short-term and long-term correlation also explain the upward and downward trend of the market. According to the Morlet wavelet which defines as followed:

$$
\psi^{M}(t)=\frac{1}{\pi^{\frac{1}{4}}} e^{i} \omega_{0} e^{\frac{-t^{2}}{2}}
$$

The term M refer to Morlet, $\omega_{0}$ is the central frequency of the wavelet and the wavenumber.

Tiwari, Bhanja, Dar, and Islam (2015) wavelet has given exciting features of conducting time series analysis and different cyclical elements. Hence the wavelet approach typically used in economics and finance when you apply than results showed multiple aspects.

\section{Continuous Wavelet}

Aloui, Hkiri, and Nguyen (2016) according to Rua and Nunes (2009) and Barunik et al., (2011) the continuous wavelet transform is following as:

$$
W_{x}(u, s)=\int_{-\infty}^{\infty} x(t) \frac{1}{\sqrt{s}} \psi\left(\overline{\frac{t-u}{s}}\right) d t
$$

The continuous wavelet has the ability to decompose and rebuild the time series data to its original form.

Aguiar-Conraria, Azevedo, and Soares (2008), the continuous wavelet transforms into mother wavelet and daughter wavelet can be given by simple scaling. The equation can be defined as follows:

$$
\psi_{s, \tau}(t):=\frac{1}{\sqrt{|S|}} \psi\left(\frac{t-\tau}{s}\right), s, \tau \in \mathbb{R}, s \neq 0 .
$$

Scaling simple wavelet means to spread or extend it if $|\boldsymbol{S}|>\mathbf{1}$ than showed a positive relationship and $|\boldsymbol{S}|<\mathbf{1}$ than showed a negative relationship. 


\section{Wavelet Coherence}

According to Shahbaz, Tiwari, and Tahir (2015), the Fourier WTC (Wavelet Coherence) approach ratio of the cross-spectrum to the product range of each series. Hence this approach showed the relationship between the two-time series and frequency. The significant variance showed the immense wavelet power of spectrum while the covariance between the time series results represented by the cross wavelet power, including all frequency or scales. Hence, Torrence and Webster expound the wavelet coherence of two-time series as follows:

$$
R_{n}^{2}(S)=\frac{\left|S\left(s^{-1} W_{n}^{X Y}(S)\right)\right|^{2}}{S\left(\left.s^{-1} W_{n}^{X}(S)\right|^{2}\right) \cdot S\left(\left.s^{-1} W_{n}^{Y}(S)\right|^{2}\right)}
$$

The smoothing operator is equivalent to one and the smoothing operator involvement in two variance time and scale as followed:

$$
S(W)=S_{\text {scale }}\left(S_{\text {time }}\left(W_{n}(S)\right)\right.
$$

So, $\boldsymbol{S}_{\text {scale }}$ represented smoothing wavelet axis and $\boldsymbol{S}_{\text {time }}$ represented by smoothing time.

\section{Results}

Table 2 - Descriptive statistics

\begin{tabular}{lccc}
\hline & CDS & SP & VI \\
\hline Mean & 5.813 & 6.272 & 1.163 \\
Median & 5.818 & 6.299 & 1.091 \\
Maximum & 5.866 & 6.374 & 1.574 \\
Minimum & 5.734 & 6.030 & 0.978 \\
Std. Dev. & 0.037 & 0.0896 & 0.169 \\
Skewness & -0.589 & -1.627 & 1.279 \\
Kurtosis & 2.655 & 5.043 & 3.626 \\
Jarque-Bera & 180.105 & 1765.149 & 829.363 \\
Probability & $(0.000)$ & $(0.000)$ & $(0.000)$ \\
Correlation matrix & & & \\
CDS & 1.000 & & \\
SP & -0.219 & 1.000 & \\
VI & -0.819 & 0.0388 & \\
\hline
\end{tabular}

Table 3 - Unit root test

\begin{tabular}{lcccc}
\hline Variable & ADF & PP & ZA & Perron \\
\hline CDS & -1.572 & -1.572 & -4.185 & -4.188 \\
SP & 53.531 & -53.561 & -3.026 & -3.957 \\
VI & -2.313 & -2.313 & -3.896 & -3.895 \\
\hline
\end{tabular}

Data series are not normally distributed, and this is not a surprising one because most of the high-frequency time series will face this normality issue. 


\section{Time Series Analysis}

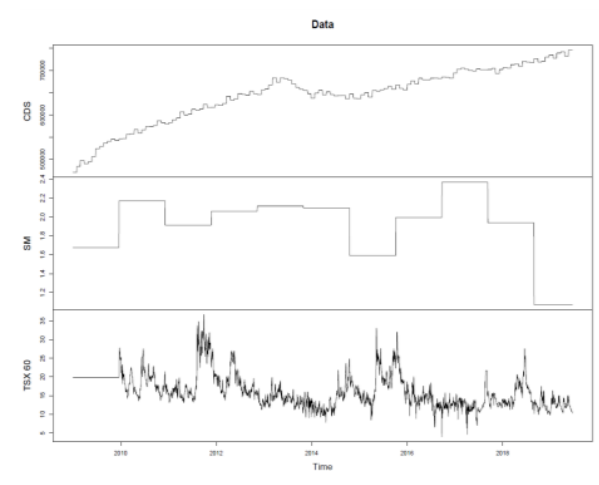

Figure 1 - Wavelet Time Series Analysis

Figure 1, showing the result of time series analysis the x-axis based on 2870 observations for the period from January 2009 to December 2019, and the y-axis described variables of the study. According to the wavelet time series analysis, data is classified in four periods starting from the short term period of 2010-2012, a mediumterm period of 2012-2014 long term 2014-2016 and a very long term period of 2016-2018.

CDS showed a low variation during the short term, medium-term period, long term and very long term period accordingly SM (Stock Market) also shown a low variation in all the four periods while the TSX 60 index has shown a high variation during the period.

\section{Continuous Wavelet Spectrum}

\section{Credit Default Swaps Market}

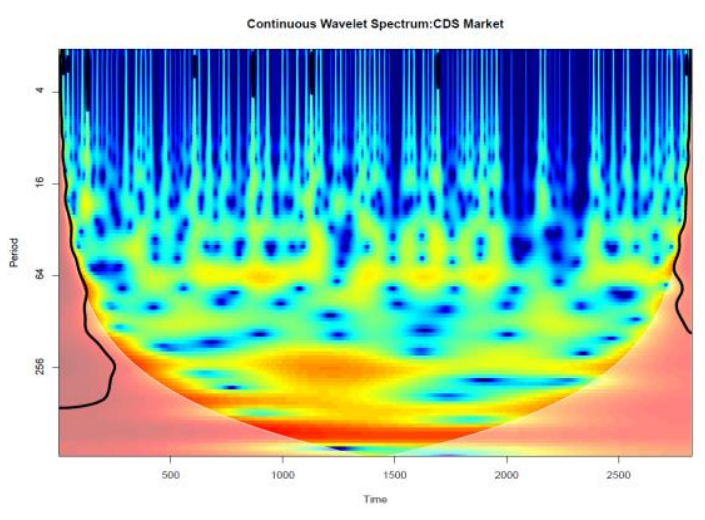

Figure 2 - Canadian Credit Default Swaps Market

Figure 2, showing the result of continuous wavelet spectrum analysis on the CDS market in the above figure $\mathrm{x}$ axis, describes a total of 2870 observations and y-axis divide the total period of January 2009 to December 2019 into four groups of short-term, long-term, medium-term, long-term and very long-term. This figure of continuous wavelet spectrum analysis of the Credit default swaps market describes that in the short-term period, there is a low variation because of the 2009 financial crisis occur. These crises badly affected the Canadian economy, and most of the insurance companies have faced insolvency, in the medium-term period there is a weak intensity, the long-term period showed a 5\% significance in the first few months afterward there is a weak intensity till the end of the period, and in the very long-term period there is a substantial variation shown in 500 to 2000 observations in the continuous wavelet spectrum plot. 


\section{Stock Market}

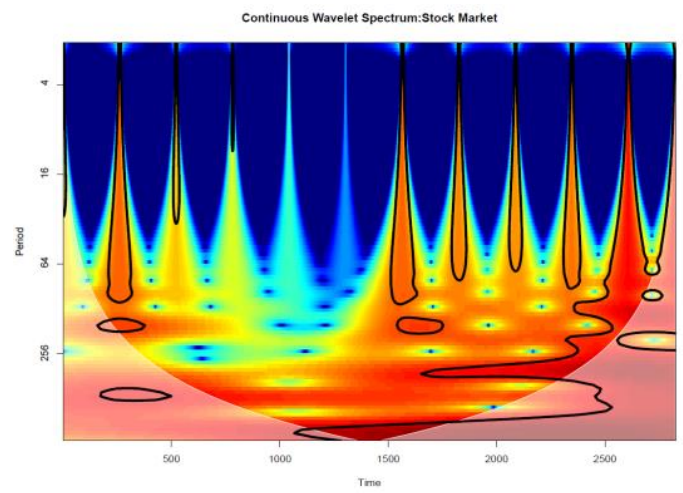

Figure 3 - Canadian Stock Market

Figure 3, showing the results of the stock market according to continuous wavelet spectrum analysis. There is a low or no variation in the short-term due to the financial crisis, which severely affected the Canadian economy, and the stock market has been collapsed. Billions of dollars were lost during these crises. The Canadian government issued US\$200 billion to rescue the stock market through the bailout package.

In a short-term, the stock market showing a low or no variation because of the 2009 financial crisis which severely affected the Canadian economy and the stock market collapsed, billions of dollar were, and the Canadian government issued US\$200 billion for rescue the stock market through bailed out the package. In the medium-term period, there is a 5\% significance and strong litter variation due to the revival of the Canadian economy. While in the long-term period, there is a $5 \%$ significance and also shown the litter bit more strong variation. After the 2019 crisis, there is an extreme variation shown in 500 to more than 2500 observations in the continuous wavelet spectrum plot.

\section{TSX 60 Volatility Index}

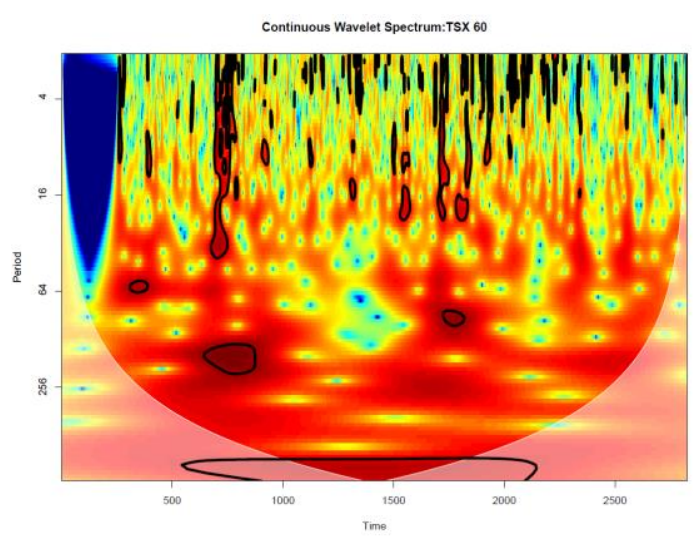

Figure 4 - Toronto Stock Exchange

Figure 4, showing the result of continuous wavelet spectrum analysis of the TSX 60 index (Toronto Stock Exchange). The analysis of the TSX 60 index in a short-term period showing a low variation and weak intensity because of the 2009 financial crisis and the top sixty companies business ratios in a day that is continuously drop down, and the investors sell their securities during this crisis. At the start of the medium-term period, there is a $5 \%$ significance and no variation, while after some period, there is a litter bit strong and weak variation observed. In a long-term period, there is a $5 \%$ significance and litter bit more strong variation, and sometimes, 
while in the very long-term period after 2019 and so on, there is an extreme variation that occurs from 500 to more than 2500. (Start from weak but with the passage of time converting towards substantial variation).

\section{Cross Wavelet Spectrum Analysis}

\section{CDS and Stock Market}

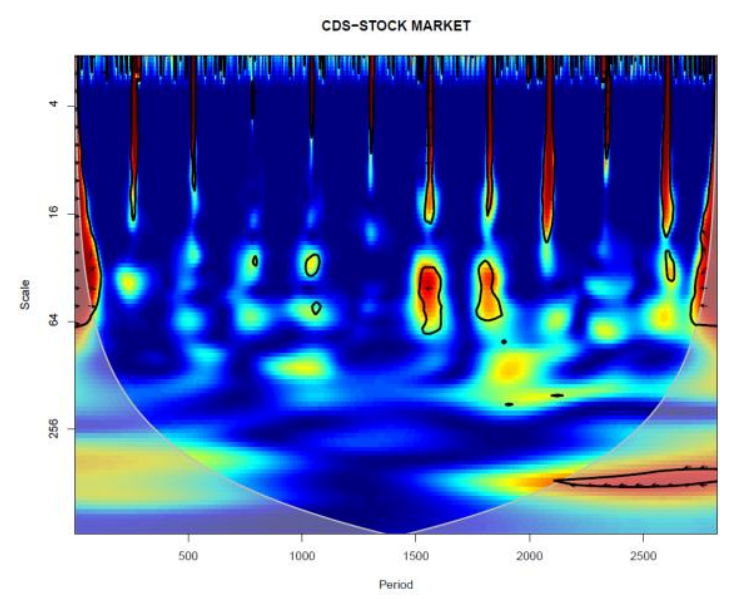

Figure 5 - Cross W avelet Spectrum Analysis Credit Default Swaps Market vs. Stock. Market

Figure 5, showing the result of cross wavelet spectrum analysis between CDS and Stock Market. In the short term, stock market showing a low or no variation in CDS. The red line with a black circle shows a 5\% significance variation between the two variables. Still, on the whole, the result shows that there is low or no variation among the CDS and stock market, in the medium-term period there is a $5 \%$ significance variation between the two variables, in the start, there is a strong relationship among both the variables. In contrast, after some period, there is no variation between the two variables. In a long-term and very long term period, there is also a $5 \%$ significant variation between the variables while there is a litter bit of substantial variation after 2000 observations.

\section{CDS and TSX 60 Volatility Index}

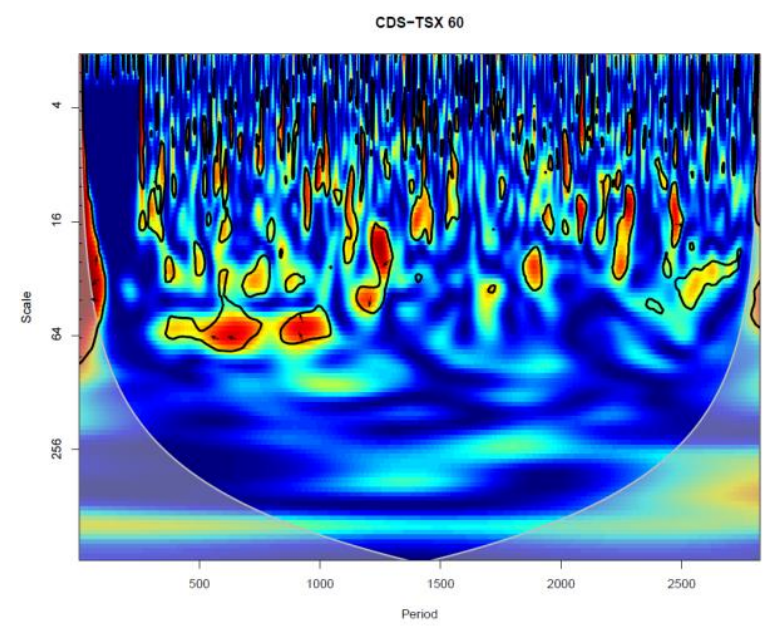

Figure 6 - Credit Default Swaps Market vs. Toronto Stock Exchange 60 Index

Figure 6, showing the result of cross wavelet spectrum analysis on the CDS market and TSX 60 index. According to the analysis, in a short-term period, there is low variation at some places among the dependent 
and independent variables, the red line with a black circle shows a 5\% significance variation between the two variables. Still, on the whole, the result shows that there is no variation among the CDS and TSX 60 index in the short-term. Similarly, in the medium-term period, there are $5 \%$ significance relationships. At the same time, at some places, there is a no and weak intensity between the variables, in a long-term period and the very longterm after 2019. So, there is a no or negative variation between the variables.

\section{Discussion}

The present study contributed to the literature by utilizing the Canadian economy data for the period from January 2009 to December 2019. This study has investigated co-movement between the Canadian CDS market, stock market, and VIX index (TXS 60 index) by using a wavelet approach. Additionally study examined the short-term, medium-term, long-term, and very long-term relationships between dependent and independent variables.

The current study utilized annual data from WDI, Canada National Statistical Agency, and S\&P Dow Jones. There are several studies worldwide which incorporate these variables and found a negative relationship among CDS and stock market as well as volatility TXS 60 index (Shahzad, Aloui and Jammazi, 2019; Norden and Weber, 2004; Hkiri, Hammoudeh, Aloui and Shahbaz, 2018; Hammoudeh and Sari, 2011; Park, 2013; Mateev, 2019; Shahzad, Mensi, Hammoudeh, Balcilar and Shahbaz, 2018; Kar, Bayat and Kayhan, 2016).

\section{Conclusion}

\section{CDS and Stock Market}

According to the cross wavelet spectrum analysis, in a short-term period, the variation between the CDS and stock market, there is a low or no variation. In contrast, a red line with a black circle showing a $5 \%$ significance variation between the two variables, on the whole, result shows that there is low or no variation among the CDS and stock market. In the medium-term, there is a 5\% significant variation between the two variables, medium-term start with a healthy relationship but gradually moving towards weak or no variation. In the longterm period, there is a $5 \%$ significant variation between the variables and, in a very long-term period, also shows $5 \%$ significance. There is a little bit of substantial variation after 2000 observations. According to the wavelet spectrum, there is a negative relationship between the CDS and stock market in the short-term and long-term period, while, on the other hand, the medium-term and very long-term period there is healthy and positive relationships between the two variables.

\section{CDS and TSX 60 Volatility Index}

According to current study findings, the relationship between the CDS market and TSX 60 VIX index in the long-term and short-term period is showing the negative relationship while on the other side the medium-term and very long-term period is showing the strong and positive relationships between the two variables. According to the cross wavelet spectrum analysis during the short-term period, there is low or no variation between the CDS market and TSX 60 Index, while the black circle shows a 5\% significance variation between the two variables. In the medium-term period, there are 5\% significance relationships between the two variables; in the long-term and the very long-term after 2019 \& so on, there is no or negative variation between the variables.

The findings of this research, provides unique information for policymaker and investor for decision in shortterm, medium-term, long-term, and very long-term investment in CDS, stock market, and TSX 60 volatility index. The study finds that both the explanatory variable having a negative relationship in the short-term and long-term while in the medium-term and very long-term shows a positive relationship; therefore, investors make their investment strategy accordingly. A future researcher should also focus on the bond market and take 
in to account a large sample to generalize the results. The further result should be verified through the Quantile on Quantile method as well.

Funding: This research received no external funding.

Acknowledgments: We acknowledge the valued guidance and comments of the editor, anonymous reviewers of the journal, and our friends, especially Mr. Saeed Khan Meo, to improve this article.

Conflicts of Interest: The authors declare no conflict of interest.

\section{References}

Aguiar-Conraria, L., Azevedo, N., \& Soares, M. J. (2008). Using wavelets to decompose the time-frequency effects of monetary policy. Physica A: Statistical Mechanics and Its Applications, 387(12), 2863-2878.

Ali, R., Butt, S. U., Butt, Z. Z., Shah, S. M., \& Sulehri, F. A. (2019). Role of Credit Information Sharing and the Funding Cost of Banks. SEISENSE Journal of Management, 2(4), 88-95.

Ali, R., Butt, Z. Z., \& Butt, S. U. (2019). Do Non-Traditional Income, Size, and Growth Affect the Performance of the Banks? SEISENSE Journal of Management, 2(3), 58-66.

Aloui, C., Hkiri, B., \& Nguyen, D. K. (2016). Real growth comovements and business cycle synchronization in the GCC countries: Evidence from time-frequency analysis. Economic Modelling, 52, 322-331.

Arain, H., Han, L., \& Meo, M. S. (2019b). Nexus of FDI, population, energy production, and water resources in South Asia: a fresh insight from dynamic common correlated effects (DCCE). Environmental Science and Pollution Research, 26(26), 27128-27137.

Arain, H., Han, L., Sharif, A., \& Meo, M. S. (2019a). Investigating the effect of inbound tourism on FDI: The importance of quantile estimations. Tourism Economics, 1354816619859695.

Asandului, M., Lupu, D., \& Claudiu MURSA, G. (2015). Munich Personal RePEc Archive Dynamic relations between CDS and stock markets in Eastern European countries. (95506).

Awan, S. A., Meo, M. S., Ghimire, A., Wu, R. Y., \& Zhuang, P. F. (2018, May). Is trade openness good or bad for environment in Pakistan; an ARDL bounds testing approach. In 4th Annual International Conference on Management, Economics and Social Development (ICMESD 2018). Atlantis Press.

Baran, L., Li, Y., Liu, C., Liu, Z., \& Pu, X. (2018). S\&P 500 index revisions and credit spreads. Review of Financial Economics, 36(4), 348-363.

Board, T. H. E. (2012). Report.

Chang, B. H., Meo, M. S., Syed, Q. R., \& Abro, Z. (2019). Dynamic analysis of the relationship between stock prices and macroeconomic variables. South Asian Journal of Business Studies.

Esen, S., Zeren, F., \& Simdi, H. (2015). CDS and Stock Market: Panel Evidence Under Cross-Section Dependency. South-Eastern Europe Journal of Economics, 13(1), 31-46.

Fareed, Z., Meo, M. S., Zulfiqar, B., Shahzad, F., \& Wang, N. (2018). Nexus of tourism, terrorism, and economic growth in Thailand: new evidence from asymmetric ARDL cointegration approach. Asia Pacific Journal of Tourism Research, 23(12), 1129-1141.

Fung, H. G., Sierra, G. E., Yau, J., \& Zhang, G. (2008). Are the U.S. stock market and credit default swap market related? Evidence from the CDX indices. Journal of Alternative Investments, 11(1), 43-61.

Hameed, W. U., Nisar, Q. A., Abbas, A., Waqas, A., \& Meo, M. S. (2019). Microfinance Institutions as a Strategic Tool to Enhance Women's Career Development in Pakistan. Asian Women, 35(2), 93-128.

Hammoudeh, S., \& Sari, R. (2011). Financial CDS, stock market and interest rates: Which drives which? North American Journal of Economics and Finance, 22(3), 257-276.

Hkiri, B., Hammoudeh, S., Aloui, C., \& Shahbaz, M. (2018). The interconnections between U.S. financial CDS spreads and control variables: New evidence using partial and multivariate wavelet coherences. International Review of Economics and Finance, 57(January), 237-257. 
Holden, C. W., \& Jacobsen, S. (n.d.). Augustin, P., Subrahmanyam, M.G., Tang, D.Y. and Wang, S.Q., 2014. Credit default swaps A survey. Foundations and Trends ${ }^{\circledR}$ in finance, 9(1-2),1-196.

Huang, S. J., Hsieh, C. T., \& Huang, C. L. (1999). Application of Morlet wavelets to supervise power system disturbances. IEEE Transactions on Power Delivery, 14(1), 235-241.

Hussain, M., Meo, M. S., \& Irshad, M. I. M. S. (2017). The Mutual Relationship Between Air Transport, Transit Time And Economic Growth: Empirical Evidence From SAARC Countries. Science International (Lahore), 29(5), 1083-1090.

Kar, M., Bayat, T., \& Kayhan, S. (2016). Impacts of Credit Default Swaps on Volatility of the Exchange Rate in Turkey: The Case of Euro. International Journal of Financial Studies, 4(3), 14.

Khan, V. J., Saeed, M., Ibrahim, T. O., \& Rizwan, M. (2018). Financial Cointegration of Emerging Economies: Evidence from Bivariate Cointegration and Granger Causality. Empirical Economic Review, 1(1), 49-70.

Masood, J., Farooq, F., \& Saeed, M. (2015). CO2 And Environment Change Evidence From Pakistan. Review of Economics and Development Studies, 1(2), 57-72.

Mateev, M. (2019). Volatility relation between credit default swap and stock market: new empirical tests. In Journal of Economics and Finance.

Mensi, W., Hkiri, B., Al-Yahyaee, K. H., \& Kang, S. H. (2018). Analyzing time-frequency comovements across gold and oil prices with BRICS stock markets: A VaR based on wavelet approach. International Review of Economics and Finance, 54, 74-102.

Meo, M. S.(2017). Impact of Political Stability, Government Effectiveness and Corruption on Stock Markets of South Asia. Journal of the Punjab University Historical Society, 30(1).

Meo, M. S., Aftab, S., Iqbal, Z., ur Rehman, F., \& Irshad, M. S. (2018). One Belt One Road: China-Pakistan Economic Corridor A Great Game Changer Initiative of the Current Century. Journal of Business \& Economics, 10(2), 58-71.

Meo, M. S., Ali, S., Khan, V. J., Haris, M., \& Rizwan, M. (2017). Indo-Pak Relationship on Line of Control after Pakistan Inclusion in Afghan Soviet War 1979. Journal of Indian Studies, 3(2), 167-181.

Meo, M. S., Chowdhury, M. A. F., Shaikh, G. M., Ali, M., \& Masood Sheikh, S. (2018). Asymmetric impact of oil prices, exchange rate, and inflation on tourism demand in Pakistan: new evidence from non-linear ARDL. Asia Pacific Journal of Tourism Research, 23(4), 408-422.

Meo, M. S., Khan, V. J., \& Rizwan, M. (2018). India-Pakistan Political Relationships; a Water War between Neighbor Countries. Journal of Indian Studies, 4(2), 217-223.

Meo, M. S., Khan, V. J., Ibrahim, T. O., Khan, S., Ali, S., \& Noor, K. (2018). Asymmetric impact of inflation and unemployment on poverty in Pakistan: new evidence from asymmetric ARDL cointegration. Asia Pacific Journal of Social Work and Development, 28(4), 295-310.

Meo, M. S., M., Hafeez, M., Shaikh, G. M., \& Shahid, M. (2018). Asymmetric Effect of Gold and Oil Prices on Stock Market Performance in Pakistan: New Evidence from Asymmetric ARDL Cointegration. Journal of Business Strategies, 12(2), 43-64.

Meo, M. S., Sabir, S. A., Arain, H., \& Nazar, R. (2020). Water resources and tourism development in South Asia: an application of dynamic common correlated effect (DCCE) model. Environmental Science and Pollution Research, 1-10.

Meo, Muhammad Saeed, Ramzan ALi, B. A. P. and M. A. (2018). Nexus of Institutional Quality and Stock Market Development: Long-Run Relationships in Dynamic Heterogeneous Panel. Journal of Independent Studies and Research: Management, Social Science and Economics, 16(2), 25-34.

Mishra, S., Sharif, A., Khuntia, S., Meo, S. A., \& Khan, S. A. R. (2019). Does oil prices impede Islamic stock indices? Fresh insights from wavelet-based quantile-on-quantile approach. Resources Policy, 62, 292-304.

Norden, L., \& Weber, M. (2004). Informational efficiency of credit default swap and stock markets: The impact of credit rating announcements. Journal of Banking and Finance, 28(11), 2813-2843.

Park, J. (2013). Information Flow between the CDS and the Stock Market and Informed Trading: Evidence 
from the Japanese CDS market. Working Paper, (17), 41-59.

Rasheed, R., Meo, M. S., Awan, R. U., \& Ahmed, F. (2019). The impact of tourism on deficit in balance of payments of Pakistan: an application of bounds testing approach to cointegration. Asia Pacific Journal of Tourism Research, 24(4), 325-332.

Reid, C. (2005). Credit Default Swaps and the Canadian Context. Financial System Review, Bank of Canada, $45-51$.

Rua, A. (2010). Measuring comovement in the time-frequency space. Journal of Macroeconomics, 32(2), 685691.

Rua, A. (2012). Wavelets in economics. Banco de Portugal, Economic Bulletin, 71-79.

Schweikhard, F. A., \& Tsesmelidakis, Z. (2013). The Impact of Government Interventions on CDS and Equity Markets. SSRN Electronic Journal, (June).

Shahbaz, M., Tiwari, A. K., \& Tahir, M. I. (2015). Analyzing time-frequency relationship between oil price and exchange rate in Pakistan through wavelets. Journal of Applied Statistics, 42(4), 690-704.

Shahzad, S. J. H., Aloui, C., \& Jammazi, R. (2019). On the interplay between US sectoral CDS, stock and VIX indices: Fresh insights from wavelet approaches. Finance Research Letters, (January), 1-9.

Shahzad, S. J. H., Mensi, W., Hammoudeh, S., Balcilar, M., \& Shahbaz, M. (2018). Distribution specific dependence and causality between industry-level U.S. credit and stock markets. Journal of International Financial Markets, Institutions and Money, 52, 114-133.

Shahzad, S. J. H., Nor, S. M., Hammoudeh, S., \& Shahbaz, M. (2017). Directional and bidirectional causality between U.S. industry credit and stock markets and their determinants. International Review of Economics and Finance, 47, 46-61.

Tiwari, A. K., Bhanja, N., Dar, A. B., \& Islam, F. (2015). Time-frequency relationship between share prices and exchange rates in India: Evidence from continuous wavelets. Empirical Economics, 48(2), 699-714.

Tokmakçioğlu, K., Özçelebİ, O., \& Manİoğlu, B. (2018). The Impacts of the Credit Default Swap on the Stock Index : Asymmetric Causality Approach for BRIC Countries Kredi Temerrüt Takasinin Hisse Senedi Endeksi Üzerindeki Etkileri : BRIC Ülkeleri İçin Asimetrik Nedensellik Yaklaşımı 1 . Introduction \& Literatu. (643), 0-2.

Tolikas, K., \& Topaloglou, N. (2017). Is default risk priced equally fast in the credit default swap and the stock markets? AN empirical investigation. Journal of International Financial Markets, Institutions and Money, $51,39-57$.

Zghal, R., Ghorbel, A., \& Triki, M. (2018). Dynamic model for hedging of the European stock sector with credit default swaps and EURO STOXX 50 volatility index futures. Borsa Istanbul Review, 18(4), 312 328. 